\title{
Touch gives new life: mechanosensation modulates spinal cord adult neurogenesis
}

R Shechter, K Baruch, M Schwartz and A Rolls

Molecular Psychiatry (2012) 17, 469; doi:10.1038/mp.2010.129

Correction to: Molecular Psychiatry (2011) 16, 342-352; doi:10.1038/mp.2010.116; published online 16 November 2010

Following the publication of the above article, the authors noted that Asya Rolls's name was not included as a co-corresponding author. The correct and complete author names appear above.

Asya Rolls's current affiliation: Stanford University, School of Medicine. Contact information: asyar@ stanford.edu

\section{Synaptic modulators Nrxn1 and Nrxn3 are disregulated in a Disc1 mouse model of schizophrenia}

SM Brown, SJ Clapcote, JK Millar, HS Torrance, SM Anderson, R Walker, A Rampino, JC Roder, PA Thomson, DJ Porteous and KL Evans

Molecular Psychiatry (2012) 17, 469; doi:10.1038/mp.2011.27

Correction to: Molecular Psychiatry (2011) 16, 585-587; doi:10.1038/mp.2010.134; published online 15 February 2011

Following the publication of the above article, the authors noted that some of the author affiliations are incorrect. Dr Clapcote is affiliated with the Institute of Membrane and Systems Biology, University of Leeds, Leeds, UK. Drs Thomson, Porteous and Evans are affiliated with Psychiatric Genetics, Medical Genetics Section, Centre for Molecular Medicine and Institute of Genetics and Molecular Medicine, Molecular Medicine Centre, Western General Hospital, University of Edinburgh, Edinburgh, UK and Centre for Cognitive Ageing and Cognitive Epidemiology, Medical Genetics Section, Molecular Medicine Centre, Western General Hospital, University of Edinburgh, Edinburgh, UK.

\section{Gestational immune activation and Tsc2 haploinsufficiency cooperate to disrupt fetal survival and may perturb social behavior in adult mice}

D Ehninger, Y Sano, PJ de Vries, K Dies, D Franz, DH Geschwind, M Kaur, Y-S Lee, W Li, JK Lowe, JA Nakagawa, M Sahin, K Smith, V Whittemore and AJ Silva

Molecular Psychiatry (2012) 17, 469-470; doi:10.1038/mp.2011.39

Correction to: Molecular Psychiatry (2012) 17, 62-70; doi:10.1038/mp.2010.115; published online 16 November 2010

Following the publication of this article, the authors noted that the TSC Natural History Database Project
Consortium should have been included within the Acknowledgments.

- Minnesota Epilepsy Group, P.A., St Paul, MN (Michael Frost, MD)

- Texas Scottish Rite Hospital for Children, Dallas, TX (Steven Sparagana, MD) 